\title{
Chinese Government Roles Transition in Addressing Global
}

\section{Warming}

\author{
Liu Hong \\ School of Public Management, Yunnan University of Finance and Economics, Kunming, P.R.China, \\ 650221 \\ (E-mail: 06liuhong@sina.com)
}

\begin{abstract}
The global warming and related changes will vary from region to region around the globe. The effects of an increase in global temperature include a rise in sea levels and a change in the amount and pattern of precipitation, as well a probable expansion of subtropical deserts. This article seeks to contribute to the Chinese government's climate change action plan by considering the role that Chinese government play in helping China's commitments under the Kyoto accord, therefore, it will consider the likely forces and the consequences of the global warming, provides a particular angle of view for environmental policy incentives to address environmental challenges, so as to build up a ecological civilization, which is the lessons learned of China ' s reform and opening up 30 years and the positive learning experience from domestic and foreign research and construction of ecological civilization.
\end{abstract}

Keywords: Ecological Civilization; Global Warming; Chinese Government; Positive Action

\section{Introduction}

Global warming is the rise in the average temperature of Earth's surface atmosphere and oceans since the late 19th century and its projected continuation. Since the early 20th century, Earth's mean surface temperature has increased by about $0.8{ }^{\circ} \mathrm{C}\left(1.4^{\circ} \mathrm{F}\right)$, with about two-thirds of the increase occurring since 1980. [1] Warming of the climate system is unequivocal, and scientists are more than 90\% certain that it is primarily caused by increasing concentrations of greenhouse gases produced by human activities such as the burning of fossil fuels and deforestation.

Climate model projections were summarized in the 2007 Fourth Assessment Report (AR4) by the Intergovernmental Panel on Climate Change (IPCC). They indicated that during the 21st century the global surface temperature is likely to rise a further 1.1 to 2.9 ${ }^{\circ} \mathrm{C}$ (2 to $5.2^{\circ} \mathrm{F}$ ) for their lowest emissions scenario and 2.4 to $6.4^{\circ} \mathrm{C}$ (4.3 to $11.5^{\circ} \mathrm{F}$ ) for their highest.[2]

\section{The Main Force of the Global Warming}

The climate system can respond to changes in external forcing. External forcing can "push" the climate in the direction of warming or cooling. Examples of external forcing include changes in atmospheric composition (e.g., increased concentrations of greenhouse gases), solar luminosity, volcanic eruptions, and variations in Earth's orbit around the Sun. Orbital cycles vary slowly over tens of thousands of years and at present are in an overall cooling trend which would be expected to lead towards an ice age, but the 20th century instrumental temperature record shows a sudden rise in global temperatures.

Greenhouse gas, particulates and soot, and solar active are the main cause of the global warming as followed: 


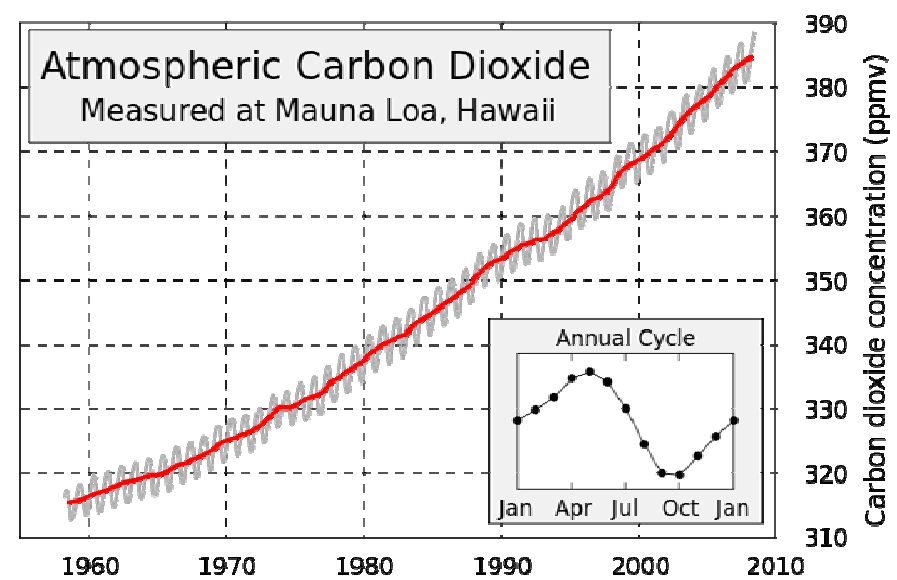

Figure 1 the carbon dioxide content from 1960 to 2010

\subsection{Greenhouse Gas}

The greenhouse effect is the process by which absorption and emission of infrared radiation by gases in the atmosphere warm a planet's lower atmosphere and surface. It was proposed by Joseph Fourier in 1824 and was first investigated quantitatively by Svante Arrhenius in 1896. Human activity since the Industrial Revolution has increased the amount of greenhouse gases in the atmosphere, leading to increased radioactive forcing from CO2, methane, troposphere ozone, CFCs and nitrous oxide.[3]

\subsection{Particulates and Soot}

Particulates and soot is mainly produced by volcanoes and human made pollutants, which exerts a cooling effect by increasing the reflection of incoming sunlight. The effects of the products of fossil fuel combustion-CO2 and aerosols-have largely offset one another in recent decades, so that net warming has been due to the increase in non-CO2 greenhouse gases such as methane.

Radioactive forcing due to particulates is temporally limited due to wet deposition which causes them to have an atmospheric lifetime of one week. Carbon dioxide has a lifetime of a century or more, and as such, changes in particulate concentrations will only delay climate changes due to carbon dioxide.

\subsection{Solar Activities}

Since 1978, output from the Sun has been measured by satellites. These measurements indicate that the Sun's output has not increased since 1978, so the warming during the past 30 years cannot be due to an increase in solar energy reaching the Earth. In the three decades since 1978, the combination of solar and volcanic activity probably had a slight cooling influence on the climate.

\section{The Impact of Global Warming}

\subsection{Ecologies Destruction}

First of all, the global warming leads to the increase of sea level, as well as the change of the precipitation and the climate pattern. Second, the great change break the biological chain and the food chain, carry with the severer consequence. For example, there is kind of a migratory bird flying from Australia to the northeast of china every summer cannot come back to China in time, because the temperature of Australia has increase recent years, bring about the a pest running rampage in the northeast and the destroy of the forest.

\subsection{Political Disputations}

Many countries are parts of the UFNCC; it suggested that every member nations has restriction of the emission of $\mathrm{CO} 2$. However, the decrease emission necessarily related to the confining consumption of energy, which become the indices of whether a country going under a high speed development.[4] In the Doha conference last year, each country's represent their country's attitude, towards the key issue about the emission of the developing countries, makes this whether work into the international political problem.

\subsection{Output of Agricultures Decreasing}

With the impact of global warming's effects, agriculture becomes increasingly difficult. Diseases and fungi will attack crops, lowering quality and production. Once abundant foods may disappear or become more expensive. The destructive, frequent natural disasters, combined with a swelling world population, 
will lead to an increased demand for staples like rice, maize, and wheat. This will cause food shortages and dramatic price increases around the world.

\subsection{Health Devastation}

The global warming causes directly various diseases on locators in regions of China, especially on new-born babies and the old, because of their low level of immune. Diseases will take over people's hometown and become uncontrollable epidemics. Malaria is spreading as the climate shift causes disease-carrying mosquitoes to move to new, different areas, and other diseases you may have thought were eradicated are reappearing. Also, new diseases are showing up in the human population more and more. Many people may die before we find cures.

\section{The Problems in Chinese Government's Environmental Monitoring}

\subsection{Poor Efficiency in Environmental Governance}

The development of the one-sided pursuit of economic interests and performance values caused the lack of government environmental governance. After the reform and opening up, government need to solve the problems of developing productivity, improving the people's living standards, enhancing the comprehensive national strength problem. Therefore, governments at all levels taking economic construction as the center, actively promote economic growth. However, it is pervasive in our country to attribute the one-sided pursuit of economic interests; economic development and social development to the growth in the number of economy. in some local government regard the GDP as a single indicator measuring the incentive to all other work. This action inevitably leads to imbalance between resources, environment and economic development.

\subsection{Low Efficiency in the Government Monopoly}

Due to the impact of the ecological environment of external factors such as market mechanism, there are a variety of failures in environmental protection and resource allocation. This provides a basis for the government intervention and the supply of public goods. Government monopoly in the supply of public goods causes the government environmental governance incentive problem.

\subsubsection{Monopoly Turns Government into}

\section{Short of Competitive Awareness and}

\section{Mechanism}

The government is short of improving the efficiency of environmental governance and motivation and pressure. As the supply of public goods monopoly, Chinese government do no need to bear the pressure of survival of the fittest, which leads to low efficiency of government supply. That is to say, because of no competition, the bureaucracy may invest too much and produce more than the social needs.

\subsubsection{The Monopoly Makes Waste of Resources and Poor Quality of Public Goods}

In environmental governance, the government lacking the motivation of profit maximization and cost minimization often tend to ignore the public environment, lacking of social response capability and substantive analysis of various environmental problems. Therefore, it is difficult to put forward the feasible innovation initiatives in the case of the decline in environmental goods supply quality.

\subsubsection{The Monopoly Bring Government \\ Officials Lazy Mind}

The government officials occupy a lot of governance resources in environmental governance. In order to avoid mistakes, government officials tend to inactive because of the lack of competition mechanism. As long as the environmental problems are not serious enough, the official's mentality of "it's better to save trouble" are prevalent, which greatly reduced the effect of government environmental governance.

\subsection{Inefficiency in Environmental \\ Management Systems}

At present, China's environmental governance adopts the management system of governments at all levels shall be responsible for the quality of the local environment, which under unified supervision and management of environmental protection. In this system, local government and the environmental protection departments implement a "dual leadership" of the local environmental protection department. The local environmental protection departments undergo the pressure from both the superior environmental protection department operational guidance in the vertical 
relationship and the administrative guidance of local government in the "block" relationship. [6] The dual leadership makes environmental governance behavior is influenced by its leader.

\section{The Measurement China Takes to Calm the Global Warming}

\subsection{Build up Ecological Civilization Urgently}

Ecological civilization is a new concept proposed by $\mathrm{Hu}$ Jintao, was highlighted in the report to the 18th National Congress of the CPC. This concept is a balance between development and nature, which is an indispensable part of the Scientific Outlook of Development.[7] Compared with previous policies on environmental protection, this concept shows progress, for it puts ecological civilization on an equal footing with the civilizations of politics, economy, society and culture. Ecological civilization construction reflects an important change in the Party's understanding of development. Rather than emphasizing economic construction as the core of development as it did in the past, the Party authorities have come to realize that development, if sustainable, must entail a list of elements including the right relationship between man and nature.

\subsection{Perform Government's Function Better}

The functions of the government are changeable according to situation and assignment. It is indispensible part of the government's functions to launch extensive publicity and popularization of knowledge about global climate change. Guiding public consciousness is in favor of building up green lifestyles and consumption patterns and is an elementary part of the government's social management as well as public service function. [8]

\subsection{Change the Idea of Development Feasibly}

Build up the comprehensive, coordinated, sustainable view is absolutely an awakening point of economic and social development in Chinese history, at the same time is a revolution to traditional GDP development standard.[9] It is a difficult process to make the officials and all the residents to really change the concept of development. However, the situation of global warming is becoming increasingly serious; we must go through this process to make it as possible as shorten. With the expanding and development of environmental protection movement and the concept of sustainable development from last mid-year, the traditional development notion of the world challenge has been questioned.

\subsection{Expand Circular Economy Energetically}

The core of the circular economic is the ' $3 \mathrm{R}$ ' priciples: reduce, reuse and recycle. Lowering the contribution of the energy input and the waste induce, enhancing the period of production use as likely, realizing the circle use of every little in daily life, are both the specific solution in common life for the enterprise. All levels officials of government should do their work compliance with the demand of these 3R principles during the premeditation and implementation of construction projects. At the same time, we appeal to the "recycling economy law" as soon as possible, therefore to strengthen the legal system construction, promote the development of circular economy. The development of new energy deserves the encouragement and support from government policy, the use of new energy needs stronger government policies to encourage and support, various levels of government should appeal energy efficiency and support research into alternative fuels.

\section{The Role China Plays in the Global Warming}

\subsection{Active Promoter of Global Effort}

In retrospect, China has always been a positive promoter of global efforts against climate change, from Rio de Janeiro to Kyoto, and from Bali to Doha--the venues of major world gatherings on the issue. China, as a responsible country, has taken a serious attitude to fighting global warming and is playing an increasingly significant role in climate negotiations, in the same time, put forward many policies and taken a series of measures and have seen effective results. To make the developing nations' voice better heard, China has set up a press and communication center in Copenhagen, and its calls to incorporate the global warming problem into the final agreement of the conference have drawn wide attention.

\subsection{Responsible Player}

One incontrovertible fact is that China has become Asia's "giant of green economy," according to a report issued this year by the UN Environment Program. China's investment 
in renewable energy last year surpassed 15.6billion U.S. dollars with an 18-percent increase from 2007. That ranked first in the Asia-Pacific region. Currently, China has become the second biggest wind power market in the world, and the biggest solar photovoltaic equipment producer.

At the Doha conference that China has issued 71 environmental labeling standards. Over the past three years, the Chinese government has adopted a series of notable measures to tackle climate change, released two white papers and formed a leading national governmental group on climate change. That's to boost the official purchase of green products, lead sustainable consumption, and help construct an environment-friendly society.

\subsection{Great Contributor}

Chinese government has reduced their unit GDP CO2 emissions by 26 percent from 1990 to 2005 , the reduction by 2020 would only reach 30-to-40-percent if government keep promises. It was estimated that China has to spend 78 billion U.S. dollars per year for the 40 to 45 -percent reduction of emission per unit of GDP, which means at least 166 dollars a year contributed by each household. Calling on the rest of the world to be aware of China's harsh realities, China ranked 106th worldwide in 2008 with per capita GDP of 3,000 U.S. dollars and millions in poverty. However, the West has been jawing about the overall CO2 emissions by China, while turning a blind eye to the fact that the per capita figures of the country are about one quarter or less of those in China.

\section{Conclusion}

In the face of the global warming, Chinese government not only implements effective supervision and encourage social organizations and individual citizens to join in the construction of ecological civilization, but also involve more market forces in the environmental protection field. Soften the progress of global warming and promoting ecological progress are a long-term task of vital importance to people's well-being and to China's future. The people pay more attention to the environmental quality and pollution issues around them and are always ready to take all kinds of measures to defend their legal rights and interests. It requires the authority to attach more importance to the environmental challenges and always put people's interests first. It is imperative for government officials giving high priority to making ecological progress and incorporates it into the country's economic, political, cultural and social development, so as to achieve lasting and sustainable development of the Chinese nation.

\section{References}

[1] Defining the Roles of the National and State Governments in the American Federal System. Richard E Levy, Stephen R McAllister, the University of Kansas Law Review, 2008.

[2] Global Warming and Extreme Events: Rethinking the Timing and Intensity of Environmental Policy. Yu-Fu Chen, Michael Funke. CESIFO WORKING PAPER NO. 3139.

[3] An Inconvenient Solution? An Economic and Political Analysis of Global Warming Policy. Michael Martin, Carleton College, 2008/ 2009.

[4] Impact of Global Warming on Rural-Urban Migration and Net Emigration in Forefront ub-Saharan Countries, Oumar Bouare, the African Migration Alliance Conference, 14-16 November 2007.

[5] Reason analysis and Countermeasures of lack of motivation of government environmental governance in our country, Fan Junyu, Zhong Zhou Journals, 2011/ 1.

[6] The Political Economy of Global Warming and its Changing Strategic Role1, Dipankar Dey, The ICFAI Journal of Environmental Economics, November, 2006.

[7] Tax Policy and Global Warming, David G. Duff, Revue Fiscale Canadienne, (2003) vol. 51, no. 6 .

[8] Public Land Leasing and the Changing Roles of Local Government in Urban China, F. Frederic Deng, Annals of Regional Science, February 12, 2003.

[9] The Determinants of Government Environmental Performance: An Empirical Analysis of Chinese Townships, Hua Wang and Wenhua Di, World Bank Policy Research Working Paper No. 2937, January 11, 2005.

[10] Reducing the Role of Government-The Chinese Experiment, Vivienne Bath, Asian Journal of Comparative Law, Vol. 3, No. 1, Article 9, 2008, Sydney Law School Research Paper No. 09/ 43. 